\title{
Satuan Biaya Rawat Inap Berdasarkan Golongan Sebab Penyakit Pada 84 Rumah Sakit Di Indonesia Tahun 2016
}

\author{
UNIT COST OF INPATIENTS BASED ON DISEASE GROUPS \\ IN 84 HOSPITALS IN INDONESIA, 2016
}

\author{
Mugi Wahidin ${ }^{1,2}$, Noor Edi Widya Sukoco ${ }^{1}$, Maria Hotnida ${ }^{3}$ \\ ${ }^{1}$ Pusat Penelitian dan Pengembangan Humaniona dan Manajemen Kesehatan, \\ Badan Penelitian dan Pengembangan Kesehatan, Kementerian Kesehatan \\ Jl. Percetakan Negara No.29, Jakarta 10560, Indonesia \\ ${ }^{2}$ Perhimpunan Ahli Epidemiologi Indonesia \\ ${ }^{3}$ Pusat Pembiayaan dan Jaminan Kesehatan, Kementerian Kesehatan \\ Email:wahids.wgn@gmail.com
}

Submitted : 20-06-2018, Revised : 27-07-2018, Revised :29-8-2018, Accepted : 29-10-2018

\begin{abstract}
Payment methods in Indonesian hospitals use INA CBGs tarrifs which are based on unit cost of disease treatments. This study aimed to determine inpatient unit costs based on 20 highest disease groups and comparation of the unit cost between class of hospitals from the secondary data of Health Financing Research which consisted of 84 government hospitals, including 9 class A hospitals, 37 class B hospitals, and 38 class $C$ hospitals. Data analysis using statistics software and a test for comparation of unit costs was conducted using Kruskal Wallis test with significancy of 0.05. Results of the analysis showed that the highest unit cost was for all types of malaria (IDR 40,865,715) and the lowest one was for diare and gastroenteritis (IDR 530,548). Generally, unit cost in class A hospitals were higher than that of class $B$ and class $C$. Whereas, the unit cost in class $C$ hospitals was higher than that of class $B$. There were significant differences in unit costs among classes of hospitals for 18 disease groups. However, there were no differences of unit costs among classes of hospitals only for malaria and intracranial injuries.
\end{abstract}

Key words: Unit cost, INA CBGs tarrif, BLU/BLUD hospitals

\begin{abstract}
Abstrak
Metode pembayaran di rumah sakit (RS) Indonesia saat ini menggunakan tarif INA CBGs yang didasarkan pada perhitungan unit cost. Tujuan analisis lanjut dari Riset Pembiayaan Kesehatan (RPK) ini untuk mengetahui besar unit cost rawat inap berdasarkan 20 golongan sebab penyakit terbesar serta perbedaan satuan biaya antar kelas yang berasal dari 84 RS BLU/BLUD di Indonesia, yaitu 9 RS kelas A, 37 RS kelas B, dan 38 RS kelas C. Pengolahan dan analisis data menggunakan software pengolah data statistik dan uji perbedaan satuan biaya menggunakan Uji Kruskal Wallis dengan derajat kemaknaan $(\alpha)$ 0,05 . Hasil analisis menunjukkan bahwa satuan biaya tertinggi adalah semua jenis malaria sebesar Rp 40.865.715, dan terendah adalah diare dan gastroenteritis ( $\mathrm{Rp}$ 530.548). Unit cost di RS kelas A secara umum lebih tinggi dari kelas B dan RS kelas C. Satuan biaya di RS kelas C secara umum lebih tinggi dari RS kelas B. Terdapat perbedaan satuan biaya antara kelas RS pada 18 golongan sebab penyakit. Namun tidak terdapat perbedaan satuan biaya antara kelas RS (A, B, dan C) untuk 2 golongan sebab penyakit yaitu Malaria dan Cedera intrakranial.
\end{abstract}

Kata kunci: Satuan biaya, Tarif INA CBGs, RS BLU/BLUD 


\section{PENDAHULUAN}

Metode pembayaran di Rumah Sakit (RS) saat ini menggunakan tarif INA CBGs yang berisi seluruh komponen sumber daya RS dalam pelayanan baik medis maupun non medis. Tarif tersebut telah ditetapkan berdasarkan Peraturan Menteri Kesehatan Nomor 52 tahun 2016 beserta perubahannya tentang Standar Tarif Pelayanan Kesehatan dalam penyelenggaraan Program Jaminan Kesehatan. Besarnya tarif tersebut ditentukan melalui perhitungan yang komprehensif dari seluruh komponen pembiayaan 1-3

Besar tarif pembiayaan pelayanan kesehatan hendaknya tidak kurang dari perhitungan biaya satuan (unit cost) sebenarnya dari seluruh pembiayaan yang diperlukan sehingga rumah sakit tidak merugi. Unit cost adalah seluruh biaya yang dibebankan dalam melaksanakan kegiatan produksi atau menghasilkan jasa atau kegiatan tertentu dibagi dengan jumlah satuan produk atau jasa yang dihasilkan. ${ }^{4}$ Unit cost didefinisikan sebagai hasil pembagian antara total cost yang dibutuhkan dibagi dengan jumlah unit produk yang dihasilkan baik barang maupun jasa. ${ }^{5}$

Berdasarkan Riset Pembiayaan Kesehatan tahun 2016, diperoleh informasi bahwa secara umum unit cost (rawat inap) RS masih lebih rendah dari tarif INA CBGs. Penelitian tersebut dilaksanakan pada 84 RS Badan Layanan Umum (BLU) dan Badan Layanan Umum Daerah (BLUD) dari 5 regional di seluruh Indonesia dan menggambarkan RS BLU/BLUD secara nasional. ${ }^{6}$

Dalam menghitung tarif INA CBGs terlebih dahulu dilakukan costing yang selanjutnya dilakukan perhitungan yang unit cost. Secara umum, metode costing dalam INA-CBGs menggunakan step-down method, namun untuk beberapa kasus digunakan metode gabungan antara step-down method Activity Based Costing (ABC). Step-down method menggunakan beberapa indikator untuk mengalokasikan seluruh biaya, mulai dengan mengalokasikan biaya dari pusat biaya overhead ke pusat biaya intermediate dan pusat biaya final serta mengalokasikan biaya dari pusat biaya intermediate ke pusat biaya final.

Tarif NA CBGs dibagi menjadi 5 regional dan dibedakan menurut kelas RS (A, B, C) dan menurut RS pemerintah maupun swasta
(1). Adapun sistem rujukan di Indonesia sudah ditetapkan dari fasilitas kesehatan tingkat pertama (FKTP) ke fasilitas kesehatan Rujukan Tingkat Lanjut (FKRTL) kelas C, kemudian FKRTL kelas B, baru ke FKRTL kelas A. ${ }^{7,8}$

Riset Pembiayaan Kesehatan 2016 juga menggunakan step-down method agar bisa dibandingkan dengan perhitungan tarif INA CBGs. Hasil riset tersebut menunjukkan unit cost untuk seluruh jenis layanan dan penyakit menurut regional dan kelas rumah sakit, sesuai tertera dalam standar tarif JKN. Pengggolongan sebab penyakit (kelompok penyakit) belum dilakukan. Golongan sebab penyakit total 363 sesuai dengan pelaporan dalam Sistem Informasi Rumah Sakit. ${ }^{9}$

Unit cost menurut golongan sebab penyakit diperlukan untuk mengetahui gambaran besarnya biaya seluruh komponen yang dikeluarkan golongan penyakit tersebut agar dapat menjadi bahan evaluasi dan penentuan tarif selanjutnya, sesuai golongan sebab penyakitnya. Selain itu, hasil penelitian juga belum menunjukkan analisis perbedaan unit cost menurut sebab penyakit.

Berdasarkan kondisi dilakukan penelitian ini yang bertujuan untuk mengetahui besar unit cost rawat inap berdasarkan 20 golongan sebab penyakit terbesar pada RS BLU/BLUD di Indonesia serta perbedaan unit cost antar kelas RS.

\section{BAHAN DAN METODE}

Desain penelitian adalah cross sectional study dengan analisis secara kuantitatif. Analisis deskriptif (univariat) untuk mengetahui besar unit cost rawat inap per kelompok sebab penyakit berdasarkan kelas RS. Analisis analitik (komparatif) untuk mengetahui perbedaan unit cost per golongan sebab penyakit antar kelas RS. Golongan sebab penyakit meliputi 20 golongan tertinggi yang sejenis meliputi seluruh biaya layanan yang diberikan dengan berbagai kondisi dan komorbid yang ada.

Data yang dikumpulkan adalah data sekunder dari data Riset Pembiayaan Kesehatan tahun 2016 berasal dari 84 RS BLU/BLUD dari 5 regional di seluruh Indonesia sesuai tarif resgional dalam Permenkes 52/2016 Rincian RS menurut kelas adalah 9 RS kelas A (11\%), 37 RS kelas B (44\%), dan 38 RS kelas C (45\%). RS kelas A 
terdiri dari $2 \mathrm{RS}$ dari regional 1, $2 \mathrm{RS}$ regional 2, 2 RS regional 3, 1 RS regional 4, dan 1 RS regional 5. RS kelas B terdiri dari $18 \mathrm{RS}$ regional 1, $4 \mathrm{RS}$ regional 2, 9 RS regional 3, 2 RS regional 4, dan $2 \mathrm{RS}$ regional 5. Sedangkan RS kelas $\mathrm{C}$ terdiri dari $13 \mathrm{RS}$ regional 1, $10 \mathrm{RS}$ regional 2, $7 \mathrm{RS}$ regional 3, 2 RS regional 4, dan $4 \mathrm{RS}$ regional 5. Konfirmasi data dilakukan untuk melalukan cross check ke 2 RS terpilih yaitu RSUP Fatmawati Jakarta (RS kelas A) dan RS Margono Soekarjo Purwokerto, Jawa Tengah (RS kelas B).

Penelitian dilaksanakan selama 2 bulan, November - Desember 2017. Pengolahan dan analisis data menggunakan software pengolah data statistik. Untuk melakukan uji perbedaan unit cost, terlebih dahulu dilakukan uji normalitas distribusi data dengan Uji Kolmogorov-Smirnov. Jika nilai $p<\alpha \quad(0,05)$ maka distribusi data disimpulkan tidak normal. Jika nilai $p \geq \alpha \quad(0,05)$ maka disimpulkan distribusi data normal. Berdasarkan uji Kolomogorv-Smirnov didapatkan nilai $\mathrm{p}>$ 0,05 yang berarti distribusi data golongan sebab penyakit tidak normal. Dengan demikian nilai tengah yang digunakan adalah nilai median.
Selanjutnya dilakukan uji perbedaan unit cost yang dilakukan dengan uji Kruskal Wallis, mengingat distribusi data tidak normal dan uji ini dilakukan untuk data independen (kelas RS) ordinal dan dependen (unit cost) rasio, dengan derajat kemaknaan $(\alpha) 0,05(10)(11)$. Jika nilai $p$ $<\alpha(0,05)$ maka disimpulkan ada perbedaan unit cost antara kelas RS (A, B, C). Jika nilai $\mathrm{p} \geq \alpha$ maka disimpulkan tidak ada perbedaan unit cost penyakit antara kelas RS (A, B, C).

\section{HASIL}

Hasil analisis menunjukkan bahwa besar unit cost (median) rawat inap (dari full cost) berdasarkan golongan sebab penyakit tertinggi untuk golongan malaria (semua jenis) sebesar Rp 40.865.715, kemudian neoplasma ganas payudara sebesar Rp 20.658.900, dan neoplasma ganas serviks uterus sebesar Rp 19.679.620. Sedangkan unit cost terendah adalah diare dan gastroenteritis oleh penyebab infeksi tertentu sebesar Rp 530.548, Penyulit kehamilan dan persalinan sebesar Rp 1.401.907, dan Demam berdarah dengue sebesar Rp 1.378.344 (tabel 1).

Tabel 1. Unit cost Menurut Golongan Sebab Penyakit

\begin{tabular}{|c|c|c|c|c|}
\hline No & No DTD & ICD-10 & Golongan Sebab Penyakit & $\begin{array}{l}\text { Unit cost (full Cost) per } \\
\text { pasien (Median, Rp) }\end{array}$ \\
\hline 1 & 2 & A01 & Demam tifoid dan paratifoid & 1.297 .288 \\
\hline 2 & 5 & A09 & Diare \& gastroenteritis oleh penyebab infeksi tertentu & 530.548 \\
\hline 3 & 007.1 & A $15.1-A 16.2$ & Tuberkulosis Paru & 2.287 .139 \\
\hline 4 & 032.1 & A91 & Demam berdarah dengue & 1.378 .344 \\
\hline 5 & 43 & B50 - B54 & Malaria (semua jenis malaria) & 40.865 .715 \\
\hline 6 & 73 & $\mathrm{C} 50$ & Neoplasma ganas payudara & 20.658 .900 \\
\hline 7 & 74 & C53 & Neoplasma ganas serviks uterus & 19.679 .620 \\
\hline 8 & 098.9 & D51- D64 & Anemia & 2.721 .115 \\
\hline 9 & 104.9 & E14 & Diabetes melitus YTT & 7.199 .883 \\
\hline 10 & 145 & $\mathrm{I} 10$ & Hipertensi esensial (primer) & 1.763 .497 \\
\hline 11 & 148 & $\mathrm{I} 20, \mathrm{I} 23-\mathrm{I} 25$ & Penyakit Jantung Iskemik & 5.012 .424 \\
\hline 12 & 155 & I64 & Strok tak menyebut perdarahan atau infark & 4.530 .497 \\
\hline 13 & 169 & J12-J18 & Pneumonia & 1.776 .324 \\
\hline 14 & 175 & J40-J44 & Bronkitis emfisema dan peny. paru obstruktif kronik & 3.148 .949 \\
\hline 15 & 184 & K29 & Gastritis dan duodenitis & 3.352 .528 \\
\hline 16 & 214.9 & N17.0-2,9-N19 & Gagal ginjal & 3.990 .796 \\
\hline 17 & 217 & N25-N29, N31-N39 & Penyakit sistem Kemih & 5.119 .258 \\
\hline 18 & 242.9 & $\mathrm{O} 20-\mathrm{O} 83$ & Penyulit kehamilan dan persalinan & 1.401 .907 \\
\hline 19 & 281 & S00-T14 & Cedera YDT lainnya YTT dan daerah badan Multipel & 4.553 .143 \\
\hline 20 & 278 & S06 & Cedera intrakranial & 5.024 .081 \\
\hline
\end{tabular}


Tabel 2. Unit cost menurut Sebab Sakit Berdasarkan Kelas RS

\begin{tabular}{|c|c|c|c|c|c|c|}
\hline No & $\begin{array}{c}\text { No } \\
\text { DTD }\end{array}$ & ICD-10 & Golongan Sebab Sakit & $\begin{array}{l}\text { Unit cost RS Tipe } \\
\text { A (median, Rp) }\end{array}$ & $\begin{array}{l}\text { Unit cost } \mathrm{RS} \text { tipe } \\
\mathrm{B}(\text { median, } \mathrm{Rp})\end{array}$ & $\begin{array}{l}\text { Unit cost RS Tipe } \\
\text { C (median, Rp) }\end{array}$ \\
\hline 1 & 2 & A01 & Demam tifoid dan paratifoid & 13.251 .154 & 800.714 & 1.297 .288 \\
\hline 2 & 5 & A09 & $\begin{array}{l}\text { Diare \& gastroenteritis oleh } \\
\text { penyebab infeksi tertentu }\end{array}$ & 6.023 .663 & 415.707 & 504.489 \\
\hline 3 & 007.1 & A15.1-A16.2 & Tuberkulosis Paru & 20.683 .432 & 2.048 .037 & 3.843 .278 \\
\hline 4 & 032.1 & A91 & Demam berdarah dengue & 3.337 .368 & 1.191 .008 & 1.111 .838 \\
\hline 5 & 43 & B50- B54 & Malaria (semua jenis) & 207.565 .413 & 45.082 .856 & 37.045 .083 \\
\hline 6 & 73 & $\mathrm{C} 50$ & Neoplasma ganas payudara & 3.818 .861 & 16.134 .975 & 34.335 .944 \\
\hline 7 & 74 & $\mathrm{C} 53$ & Neoplasma ganas serviks uterus & 15.645 .752 & 13.521 .711 & 44.703 .429 \\
\hline 8 & 098.9 & D51- D64 & Anemia & 6.888 .500 & 1.561 .650 & 2.341 .794 \\
\hline 9 & 104.9 & E14 & Diabetes melitus YTT & 48.849 .924 & 4.711 .574 & 7.199 .883 \\
\hline 10 & 145 & $\mathrm{I} 10$ & Hipertensi esensial (primer) & 44.226 .954 & 1.850 .502 & 1.221 .110 \\
\hline 11 & 148 & $\mathrm{I} 20, \mathrm{I} 23-\mathrm{I} 25$ & Penyakit Jantung Iskemik & 6.670 .465 & 2.900 .230 & 9.808 .061 \\
\hline 12 & 155 & I64 & $\begin{array}{l}\text { Strok tak menyebut perdarahan } \\
\text { atau infark }\end{array}$ & 61.713 .932 & 2.974 .942 & 6.317 .377 \\
\hline 13 & 169 & J12-J18 & Pneumonia & 5.130 .768 & 1.465 .027 & 1.439 .326 \\
\hline 14 & 175 & J40-J44 & $\begin{array}{l}\text { Bronkitis emfisema dan peny. } \\
\text { paru obstruktif kronik }\end{array}$ & 25.698 .640 & 2.434 .739 & 3.148 .949 \\
\hline 15 & 184 & K29 & Gastritis dan duodenitis & 15.878 .531 & 2.567 .554 & 3.381 .212 \\
\hline 16 & 214.9 & N17.0-2,9-N19 & Gagal ginjal & 8.044 .813 & 2.658 .665 & 6.721 .217 \\
\hline 17 & 217 & N25-N29, N31-N39 & Penyakit sistem Kemih & 22.703 .585 & 3.514 .879 & 5.704 .009 \\
\hline 18 & 242.9 & $\mathrm{O} 20-\mathrm{O} 83$ & $\begin{array}{l}\text { Penyulit kehamilan dan persali- } \\
\text { nan }\end{array}$ & 6.479 .865 & 979.133 & 1.372 .202 \\
\hline 19 & 281 & S00 -T14 & $\begin{array}{l}\text { Cedera YDT lainnya YTT dan } \\
\text { daerah badan Multipel }\end{array}$ & 13.906 .666 & 5.543 .741 & 3.086 .785 \\
\hline 20 & 278 & S06 & Cedera intrakranial & 7.250 .123 & 3.642 .562 & 5.008 .646 \\
\hline
\end{tabular}

Tabel 3. Analisis Perbedaan Unit cost Rawat Inap Menurut Golongan Sebab Penyakit berdasar Kelas RS

\begin{tabular}{|c|c|c|c|c|c|}
\hline No & Golongan Sebab Penyakit & Kelas RS & $\mathbf{N}$ & $\begin{array}{c}\text { Mean Rank } \\
\text { Unit cost }\end{array}$ & Nilai p \\
\hline \multirow[t]{3}{*}{1} & Demam tifoid dan paratifoid & Kelas A & 9 & 72,89 & 0,000 \\
\hline & & Kelas B & 37 & 37,08 & \\
\hline & & Kelas C & 38 & 40,58 & \\
\hline \multirow[t]{3}{*}{2} & Diare \& gastroenteritis oleh penyebab infeksi tertentu & Kelas A & 9 & 75,78 & 0,000 \\
\hline & & Kelas B & 37 & 38,32 & \\
\hline & & Kelas C & 38 & 38,68 & \\
\hline \multirow[t]{3}{*}{3} & Tuberkulosis Paru & Kelas A & 8 & 72,50 & 0,000 \\
\hline & & Kelas B & 37 & 31,95 & \\
\hline & & Kelas C & 37 & 44,35 & \\
\hline \multirow[t]{3}{*}{4} & Demam berdarah dengue & Kelas A & 9 & 62,79 & 0,013 \\
\hline & & Kelas B & 37 & 36,49 & \\
\hline & & Kelas C & 37 & 42,46 & \\
\hline \multirow[t]{3}{*}{5} & Malaria (semua jenis) & Kelas A & 8 & 38,12 & 0,408 \\
\hline & & Kelas B & 24 & 28,83 & \\
\hline & & Kelas C & 28 & 29,75 & \\
\hline \multirow[t]{3}{*}{6} & Neoplasma ganas payudara & Kelas A & 9 & 23,00 & 0,011 \\
\hline & & Kelas B & 34 & 35,82 & \\
\hline & & Kelas C & 34 & 46,41 & \\
\hline \multirow[t]{2}{*}{7} & Neoplasma ganas serviks uterus & Kelas A & 9 & 28,89 & 0,007 \\
\hline & & Kelas B & 33 & 30,27 & \\
\hline
\end{tabular}




\begin{tabular}{|c|c|c|c|c|c|}
\hline \multirow{4}{*}{8} & \multirow{3}{*}{ Anemia } & Kelas C & 30 & 45,63 & \multirow{3}{*}{0,031} \\
\hline & & Kelas A & 9 & 60,44 & \\
\hline & & Kelas B & 36 & 37,11 & \\
\hline & & Kelas C & 37 & 41,16 & \\
\hline \multirow[t]{3}{*}{9} & \multirow[t]{3}{*}{ Diabetes melitus YTT } & Kelas A & 8 & 61,12 & \multirow[t]{3}{*}{0,015} \\
\hline & & Kelas B & 36 & 35,06 & \\
\hline & & Kelas C & 35 & 40,26 & \\
\hline \multirow[t]{3}{*}{10} & \multirow[t]{3}{*}{ Hipertensi esensial (primer) } & Kelas A & 9 & 72,00 & \multirow[t]{3}{*}{0,000} \\
\hline & & Kelas B & 27 & 42,89 & \\
\hline & & Kelas C & 36 & 32,44 & \\
\hline \multirow[t]{3}{*}{11} & \multirow[t]{3}{*}{ Penyakit Jantung Iskemik } & Kelas A & 9 & 42,78 & \multirow[t]{3}{*}{0,004} \\
\hline & & Kelas B & 37 & 31,81 & \\
\hline & & Kelas C & 35 & 50,26 & \\
\hline \multirow[t]{3}{*}{12} & \multirow[t]{3}{*}{ Strok tak menyebut perdarahan atau infark } & Kelas A & 8 & 67,88 & \multirow[t]{3}{*}{0,000} \\
\hline & & Kelas B & 35 & 31,26 & \\
\hline & & Kelas C & 37 & 43,32 & \\
\hline \multirow[t]{3}{*}{13} & \multirow[t]{3}{*}{ Pneumonia } & Kelas A & 9 & 68,44 & \multirow[t]{3}{*}{0,001} \\
\hline & & Kelas B & 36 & 35,36 & \\
\hline & & Kelas C & 36 & 39,37 & \\
\hline \multirow[t]{3}{*}{14} & \multirow[t]{3}{*}{ Bronkitis emfisema dan peny. paru obstruktif kronik } & Kelas A & 9 & 72,44 & \multirow[t]{3}{*}{0,000} \\
\hline & & Kelas B & 37 & 35,78 & \\
\hline & & Kelas C & 37 & 40,81 & \\
\hline \multirow[t]{3}{*}{15} & \multirow[t]{3}{*}{ Gastritis dan duodenitis } & Kelas A & 9 & 64,56 & \multirow[t]{3}{*}{0,004} \\
\hline & & Kelas B & 35 & 37,31 & \\
\hline & & Kelas C & 36 & 37,58 & \\
\hline \multirow[t]{3}{*}{16} & \multirow[t]{3}{*}{ Gagal ginjal } & Kelas A & 9 & 54,11 & 0,016 \\
\hline & & Kelas B & 37 & 32,97 & \\
\hline & & Kelas C & 34 & 45,09 & \\
\hline 17 & Penyakit sistem Kemih & Kelas A & 9 & 60,78 & 0,004 \\
\hline & & Kelas B & 36 & 33,03 & \\
\hline & & Kelas C & 34 & 41,88 & \\
\hline 18 & Penyulit kehamilan dan persalinan & Kelas A & 9 & 71,78 & 0,000 \\
\hline & & Kelas B & 36 & 36,94 & \\
\hline & & Kelas C & 36 & 37,36 & \\
\hline 19 & Cedera YDT lainnya YTT dan daerah badan Multipel & Kelas A & 8 & 59,00 & 0,011 \\
\hline & & Kelas B & 37 & 42,27 & \\
\hline & & Kelas C & 34 & 33,06 & \\
\hline 20 & Cedera intrakranial & Kelas A & 9 & 51,44 & 0,122 \\
\hline & & Kelas B & 35 & 34,74 & \\
\hline & & Kelas C & 31 & 37,77 & \\
\hline
\end{tabular}

Hasil analisis unit cost rawat inap (median) menurut golongan sebab sakit berdasarkan kelas RS terlihat berbeda. Secara umum, unit cost di RS kelas A lebih tinggi dari kelas B dan RS kelas C. Tidak semua unit cost di RS kelas A lebih tinggi daripada RS kelas B atau C. Ada 1 unit cost di RS kelas A lebih rendah dari RS kelas B dan RS kelas $\mathrm{C}$ yaitu unit cost neoplasma ganas payudara.

Unit cost di RS kelas $C$ secara umum lebih tinggi dari RS kelas B. Lima belas dari dua puluh unit cost menurut golongan sebab sakit di RS kelas
C lebih tinggi dari RS kelas B. Hanya ada 5 unit cost di RS kelas B yang lebih tinggi dari RS kelas $\mathrm{C}$, yaitu demam berdarah dengue, malaria (semua jenis), hipertensi esensial (primer), pneumonia, dan cedera YDT lainnya YTT dan daerah badan multipel. Selengkapnya pada Tabel 2.

Hasil analisis uji perbedaan unit cost rawat inap (uji Kruskal Wallis menurut golongan sebab sakit menunjukkan ada perbedaan signifikan unit cost antar kelas RS (A, B, dan C), dengan nilai $\mathrm{p}<0,05$, hampir pada semua (18 dari 20) jenis 
golongan sebab sakit. Hanya 2 golongan sebab penyakit yang tidak terdapat perbedaan signifikan unit cost antar kelas RS yaitu malaria dan cedera intrakranial (tabel 3).

\section{PEMBAHASAN}

Hasil analisis menunjukkan bahwa besar unit cost (median) rawat inap (dari full cost) berdasarkan golongan sebab sakit tertinggi untuk golongan malaria (semua jenis) sebesar $\mathrm{Rp}$ 40.865.715. Malaria merupakan penyakit endemik yang memerlukan pembiayaan cukup besar, untuk pemeriksaan klinis, laboratorium, bahkan ICU jika diperlukan. Jika kasus sedikit maka pembagi unit cost menjadi lebih sedikit yang menyebabkan unit cost menjadi besar.

Hasil analisis juga menunjukkan unit cost terendah adalah Diare \& gastroenteritis oleh penyebab infeksi tertentu sebesar Rp 530.548. Hal ini diduga karena diare dan gastroenteritis merupakan penyakit yang mudah dideteksi dan juga mudah disembuhkan dengan obat-obatan yang tersedia. Dengan kasus yang cukup banyak maka unit cost menjadi rendah.

Unit cost malaria di RS kelas A sangat besar ( $R p$ 207.565.413) dibanding RS kelas B dan RS kelas C. Hal ini berhungan dengan distribusi data yang tidak normal, dengan perbedaan jumlah pasien yang dilayani pada waktu studi sangat berbeda yaitu pasien RS kelas A total 194, RS kelas B 215, dan RS kelas C 2.568.

Unit cost golongan sebab penyakit tidak dapat dibandingkan secara langsung dengan tarif INA CBGs, karena perbedaan pengelompokkan penyakit. Akan tetapi unit cost dapat dibandingkan dengan tarif yang mendekati kelompok sebab penyakit tersebut. unit cost malaria jauh lebih tinggi daripada tarif INA CBGs untuk penyakit infeksi bakteri dan parasit lain-lain (berat) sebesar Rp 6.632.500. Akan tetapi perhitungan unit cost dilakukan untuk seluruh jenis cost baik direct maupun indirect sehingga perbedaan tampak besar.

Unit cost hipertensi sebesar Rp 44.226.954 di RS kelas A lebih tinggi daripada tarif INA CBGs (hipertensi berat) $\mathrm{Rp}$ 6.216.500. tetapi rata-rata uint cost seluruh kelas RS (Rp 1.763.497) masih lebih rendah dari tarif INA CBGs.

Unit cost adalah seluruh biaya yang dibebankan dalam melaksanakan kegiatan produksi atau menghasilkan jasa atau kegiatan tertentu dibagi dengan jumlah satuan produk atau jasa yang dihasilkan. ${ }^{4}$ Pendapat lain mengatakan bahwa unit cost didefinisikan sebagai hasil pembagian antara total cost yang dibutuhkan dibagi dengan jumlah unit produk yang dihasilkan, baik maupun jasa. ${ }^{5}$

Beberapa hasil lain menunjukkan unit cost yang bervariasi. Unit cost penyakit jantung lebih rendah dibanding hipertensi esensial, dan unit cost RS C lebih besar dari RS kelas A, unit cost jantung iskemik di RS kela A hampir sama dengan unit cost anemia. Unit cost stroke (Rp 4,5 juta) hampir sama dengan gagal ginjal (Rp 3,9 juta) dan anemia (Rp 2,7 juta). Hal ini terkait normalitas data dan perbedaan jumlah pasien yang dilayani sebagai dasar pembagi jumlah unit cost serta komponen biaya yang bervariasi (direct dan indirect).

Hasil analisis unit cost rawat inap menurut golongan sebab sakit berdasarkan kelas RS terlihat berbeda. Secara umum, unit cost di RS kelas A lebih tinggi dari kelas B dan RS kelas C. Tidak semua unit cost di RS kelas A lebih tinggi daripada RS kelas B atau C. Ada 1 unit cost di RS kelas A lebih rendah dari RS kelas B dan RS kelas $\mathrm{C}$ yaitu unit cost neoplasma ganas payudara. Hal ini kemungkinan karena kasus kanker payudara di RS kelas C (25 kasus) dan RS kelas B (116 kasus) lebih sedikit dibanding kasus di RS kelas A (805 kasus). Kanker merupakan penyakit yang dideteksi di rumah sakit dengan fasilitas yang cukup.

Unit cost di RS kelas C secara umum lebih tinggi dari RS kelas B. Lima belas dari dua puluh unit cost menurut golongan sebab sakit di RS kelas $\mathrm{C}$ lebih tinggi dari RS kelas B. Hanya ada 5 unit cost di RS kelas B yang lebih tinggi dari RS kelas $\mathrm{C}$, yaitu Demam berdarah dengue, Malaria (semua jenis), Hipertensi esensial (primer), Pneumonia, dan Cedera YDT lainnya YTT dan daerah badan Multipel. Hal ini menjadi pertanyaan mengapa unit cost di RS kelas $\mathrm{C}$ justru lebih tinggi dari RS kelas A. Metode perhitungan Step Down dalam menghitung unit cost memiliki beberapa kriteria terkait rincian kegiatan yang harus ditentukan.

Perhitungan dengan metode ini ini dilakukan distribusi biaya unit penunjang kepada unit penunjang lain dan unit produksi. Distribusi biaya dilakukan secara berturut-turut dimulai dengan 
unit penunjang yang biasanya terbesar. Biaya unit penunjang tersebut di distribusikan ke unitunit lain (penunjang dan produksi yang relevan). Proses ini terus dilakukan sampai semua biaya dari unit penunjang habis didistribusikan ke unit produksi. ${ }^{12}$ Hal ini kemungkinan menyebabkan perhitungan di RS kelas $\mathrm{C}$ menjadi kurang detail sehingga dibuat sama untuk semua tindakan, yang tentu menyebabkan biaya menjadi lebih besar.

Perhitungan unit cost dalam Riset Pembiayaan Kesehatan tahun 2016 meliputi meliputi akomodasi, visite dokter, tindakan keperawatan, obat dan BHP, laboratorium, radiologi, UGD, konsultasi, operasi dan lainnya dengan katagori overhead, intermediate, dan final. ${ }^{6}$ Perhitungan ini sesuai dengan Peraturan Menteri Kesehatan Nomor 52 tahun 2016 yang menyebutkan bahwa tarif FKRTL meliputi pelayanan: a. administrasi pelayanan; $b$. Pemeriksaan, pengobatan dan konsultasi medis dasar di unit gawat darurat; c. pemeriksaan, pengobatan dan konsultasi spesialistik oleh dokter spesialis dan subspesialis; d. tindakan medis spesialistik, baik bedah maupun nonbedah sesuai dengan indikasi medis; e. pelayanan obat dan bahan medis habis pakai; f. pelayanan penunjang diagnostik lanjutan sesuai dengan indikasi medis; g. rehabilitasi medis termasuk rehabilitasi psikososial; h. pelayanan darah; i. pelayanan kedokteran forensik klinik; j. pelayanan jenazah (pemulasaran jenazah) pada pasien yang meninggal di fasilitas kesehatan (tidak termasuk peti jenazah); k. pelayanan keluarga berencana termasuk tubektomi interval, sepanjang tidak termasuk dibiayai oleh pemerintah; 1 . perawatan inap non-intensif; dan $\mathrm{m}$. perawatan inap di ruang intensif. ${ }^{1-3}$

Tarif INA-CBG merupakan tarif paket yang meliputi seluruh komponen sumber daya rumah sakit yang digunakan dalam pelayanan baik medis maupun nonmedis. Tarif INA-CBG terdiri atas tarif rawat jalan dan tarif rawat inap, dengan 6 (enam) kelompok tarif yaitu untuk RSUP Nasional dan khusus, RS pemerintah dan swasta kelas A, RS pemerintah dan swasta kelas B, RS pemerintah dan swasta kelas C, dan RS pemerintah dan swasta kelas D. Adapun tarif rawat inap terdiri dari tarif rawat inap kelas 1, kelas 2, dan kelas 3. Tarif rawat jalan dan rawat inap di rumah sakit yang bekerjasama dengan BPJS Kesehatan. ${ }^{1-3}$
Di beberapa negara Eropa seperti Austria, Inggris, Estonia, Finlandia, Perancis, Jerman, Irlandia, Beland, Polandia, Spanyol, and Swedia, tarif ditetapkan dengan Diagnostic Related Groups (DRGs). Hasil penelitian Kreinsen et al menunjukkan bahwa biaya pembedahan kanker payudara termasuk mastektomy antara 577 Euro sampai 5780 Euro. $^{13}$

Pengobatan penyakit hendaknya dilakukan secara cost-efective sehingga memberikan manfaat yang besar dengan biaya yang rasional. Pembiayaan penyakit jantung di Belanda menunjukkan biaya lebih cost efective untuk pasien laki-laki usia $>50$ tahun dan memerlukan monitoring dan edukasi terus-menerus. ${ }^{14}$

Beberapa penelitian menujukkan tarif INA CBGs ada yang lebih rendah maupun lebih tinggi dari perhitungan di RS. Penelitian di sebuah RS di Palembang menunjukkan tarif pengobatan Coronary Artery Disease pada tingkat keparahan rendah lebih tinggi dari tarif INA CBGs. Akan tetapi, tarif penyakit tersebut keparahan lebih tinggi mempunyai tarif lebih rendah dari INA CBGs. ${ }^{15}$

Penelitian di RS di Sukoharjo oleh Wijayanti dan Sugiarsi menunjukkan bahwa terdapat perbedaan signifikan biaya riil dengan tarif INA CBGs. Perbedaan tersebut terkait dengan variasi standar tarif, leng of stay, pemanfaat software, akurasi diagnosis, koding, dan kekurangan clinical pathway di RS. ${ }^{16}$

Demikian juga dengan penelitian di RS Sardjito Yogyakarta tahun 2014 menunjukkan bahwa terdapat perbedaan cost riil dengan tarif INA CBGs untuk pasien Diabetes Mellitus. Faktor yang mempengaruhi adalah pemeriksaan patologis, darah, dan obat-obatan. ${ }^{17}$

Penelitian cost leukemia oleh Indriani et al tahun 2013 diRS Sardjito Yogyakarta menunjukkan bahwa pemeriksaan kimia klinik meliputi mikrobiologi darah, ureum, magnesium, creatine kinase MB (blood) menyebabkan kesenjangan tarif semakin meningkat. Ketidakefisienan penggunaan sumber daya laboratorium pada pemeriksaan kimia klinik terdapat pada kelompok pasien tingkat keparahan ringan. ${ }^{18}$

Penelitian Budiarto dan Sugiharto pada 10 $\mathrm{RS}$, biaya pengobatan rawat inap berdasarkan tarif rumah sakit kelas A jauh lebih besar dibandingkan kelas B dan RS Khusus, biaya klaim berdasarkan 
INA-CBGs jauh lebih besar di rumah sakit kelas A dibanding kelas $\mathrm{B}$ dan RS Khusus. Biaya pengobatan rawat inap berdasarkan tarif rumah sakit kelas A jauh lebih besar dibandingkan kelas B dan RS Khusus, biaya klaim berdasarkan INACBGs jauh lebih besar di rumah sakit kelas A dibanding kelas B dan RS Khusus. Komponen biaya yang banyak peruntukannya adalah biaya akomodasi, tindakan ruangan, pemeriksaan laboratorium, tindakan intervensi non bedah untuk jantung, tindakan operasi untuk kanker serta biaya obat-obatan. Biaya penggantian klaim penyakit katastropik berdasarkan INA CBGs lebih besar dibandingkan dengan biaya riil berdasarkan tarif rumah sakit.19

Adapun penelitian Rahayuningrum, et al tahun 2016 di beberapa RS di Jawa Tengah menunjukkan bahwa rata-rata cost rawat inap lebih rendah dari tarif INA-CBGs. Jenis RS, penggunaan ICU, length of stay merupakan faktor determinan penting dalam cost rawat inap. ${ }^{20}$

Kelengkapan data berhubungan dengan klaim INA CBGs. Penelitian Hasanah, et al di RS di Wonosobo menunjukkan bahwa kelengkapan data rekam medis berhubungan dan klaim INA CBGs (jumlah klaim dan keparahan) Faktor yang berhubungan adalah ketelitian koder, kelengkapan diagnosis sekunder. ${ }^{21}$

Berdasarkan informasi yang diperoleh dari 2 rumah sakit yang dikunjungi, metode penghitungan unit cost berbeda-beda. Rumah sakit tipe $\mathrm{B}$ yang dikunjungi menggunakan metode double distribution dan hasilnya unit cost lebih tinggi dari tarif INA CBGs (perhitungan 2017). Metode double distribution dilakukan karena lebih mudah untuk penghitungan mengingat kesulitan dalam menghitung secara rinci setiap kegiatan pelayanan tidak langsung (non direct). Namum demikian, metode ini mempunyai kelemahanan yaitu biaya diambil berdasarkan ratio unit bukan pengeluaran Riil, penghitungan unit cost bukan berdasarkan penyakit tapi berdasarkan biaya unit. Saran yang diberikan adalah penghitungan unit cost berdasarkan Real Cost masing-masing unit dan Menggunakan Activity Based Costing (ABC) untuk masing-masing penyakit untuk Tarif INA CBGs.

Adapun di salah satu RS tipe A diperoleh informasi bahwa unit cost dihitung menggunakan metode Activity Based Costing dan hasilnya juga lebih tinggi dari tarif INA CBGs. Metode Activity Based Costing ini dilakukan secara rinci untuk menilai total biaya di setiap kegiatan, sehingga lebih menggambarakan real cost di RS, baik untuk pelayanan langsung maupun tidak langsung. Saran yang diberikan adalah agar penetapan tarif INA CBGs disesuaikan dengan metode yang dikembangkan di RS sesuai dengan kelas RS dan regionalnya.

Beberapa penelitian juga menujukkan bahwa metode $\mathrm{ABC}$ lebih tinggi hasilnya dibanding metode double distribution. Penelitian di sebuah RS paru menujukkan perhitungan dengan metode $\mathrm{ABC}$ lebih tinggi dibanding metode double distribution. ${ }^{22}$ Akan tetapi, metode ABC juga masih perlu disempurnakan. ${ }^{23}$

Hasil analisis uji perbedaan pada penelitian ini menunjukkan ada pebedaan unit cost rawat inap (uji median) menurut golongan sebab sakit antar kelas RS (A, B, dan C) pada 15 jenis golongan sebab sakit. Terdapat lima jenis golongan sebab sakit yang tidak tedapat perbedaan unit cost antar kelas RS, yaitu Malaria (semua jenis malaria), Neoplasma ganas payudara, Anemia, Diabetes melitus YTT, dan Penyakit sistem Kemih. Kelima golongan sebab penyakit yang tidak ada perbedaan unit cost antar kelas RS kemungkinan karena penyakit tersebut ditangani secara merata di RS kelas A, RS kelas B, dan RS kelas B.

\section{KESIMPULAN}

1. Besar unit cost rawat inap RS BLU/BLUD tertinggi adalah malaria (semua jenis) sebesar Rp 40.865.715, dan terendah adalah Diare \& gastroenteritis oleh penyebab infeksi tertentu (Rp 530.548).

2. Besar unit cost rawat inap di RS kelas A secara umum lebih tinggi dari kelas B dan RS kelas C. Unit cost di RS kelas C secara umum lebih tinggi dari RS kelas B.

3. Terdapat perbedaan unit cost antara kelas RS (A, B, dan C) untuk 18 golongan sebab penyakit, yaitu: demam tifoid dan paratifoid, diare dan gastroenteritis oleh penyebab infeksi tertentu, tuberkulosis paru, demam berdarah dengue, neoplasma ganas serviks uterus, hipertensi esensial (primer), penyakit jantung iskemik, strok tak menyebut perdarahan atau infark, pneumonia, bronkitis emfisema dan 
penyakit paru obstruktif kronik, gastritis dan duodenitis, gagal ginjal, penyulit kehamilan dan persalinan, cedera YDT lainnya YTT, neoplasma ganas payudara, anemia, diabetes melitus YTT, dan penyakit sistem kemih.

4. Tidak terdapat perbedaan unit cost antara kelas RS (A, B, dan C) Malaria (semua jenis malaria) dan cedera intrakranial.

\section{UCAPAN TERIMA KASIH}

Terima kasih kepada Kepala Puslitbang Humaniora dan Manajemen Kesehatan, Direktur Pelayanan Medis RSUP Fatmawati, Direktur Pelayanan Medis RSUD Margono Soekarjo Puswokerto, yang telah memberikan izin dan mendukung pelaksanaan penelitian ini.

\section{DAFTAR RUJUKAN}

1. Kemenkes RI. Peraturan Menteri Kesehatan R.I. Nomor 52 tahun 2016 tentang Standar Tarif Pelayanan Kesehatan dalam Penyelenggaraan Program Jaminan Kesehatan. Jakarta: Kementerian Kesehatan RI; 2016.

2. Kemenkes RI. Peraturan Menteri Kesehatan R.I. Nomor No 64 Tahun 2016 Tentang Perubahan Atas Peraturan Menteri Kesehatan Nomor 52 Tahun 2016 Tentang Standar Tarif Pelayanan Kesehatan Dalam Penyelenggaraan Program Jaminan Kesehatan. Jakarta: Kementerian Kesehatan RI; 2016.

3. Kemenkes RI. Peraturan Menteri Kesehatan R.I. Nomor 4 Tahun 2017 tentang Perubahan Kedua atas Peraturan Menteri Kesehatan Nomor 52 tahun 2016 tentang Standar Tarif Pelayanan Kesehatan dalam Penyelenggaraan Program Jaminan Kesehatan. Jakarta: Kementerian Kesehatan RI; 2017.

4. Supriyono RA. Akuntansi Biaya.Buku 1 Edisi 2. Yogyakarta: Penerbit BPFE; 2011.

5. Hansen DR and MMM. Manajemen Accounting Fourth Edition. Cincinnati, Ohio: South Western College Publishing; 2009.

6. Kemenkes RI. Laporan Riset Pembiayaan Kesehatan pada Fasilitas Kesehatan Rujukan Tingkat Lanjut (FKRTL) tahun 2016. Jakarta: Kementerian Kesehatan RI; 2017.

7. RI P. Peraturan Presiden R.I. Nomor 12 tahun 2013 tentang Jaminan Kesehatan. 2013.
8. Kemenkes RI. Peraturan Menteri Kesehatan Nomor 71 tahun 2013 tentang Pelayanan Kesehatan pada Jaminan Kesehatan Nasional. Jakarta: Kementerian Kesehatan RI; 2013.

9. Kemenkes RI. Peraturan Menteri Kesehatan R.I. Nomor 82 tahun 2013 tentang Sistem Informasi Manajemen Rumah Sakit. Jakarta: Kementerian Kesehatan RI; 2013.

10. Sugiyono. Statistika untuk Penelitian. Bandung: CV Alfabeta; 2003.

11. Santoso S. Statistik non Parametrik Konsep dan Aplikasi dengan SPSS. Jakarta: Elex Media Komputindo; 2010.

12. Conteh L, Walker D. Cost and unit cost calculations using step-down accounting. Health Policy Plan. 2004;19(2):127-35.

13. Scheller-kreinsen D, Quentin W, Geissler A, Busse R. Breast cancer surgery and diagnosisrelated groups ( DRGs ): Patient classi fi cation and hospital reimbursement in 11 European countries. 2013;22.

14. Issa V, Ayub-ferreira SM, Wijk SS. CostEffectiveness Benefits of a Disease Management Program : Short Title : Benefits of a Disease Management Program Authors : Institutions: J Card Fail [Internet]. 2018; Available from: https://doi.org/10.1016/j. cardfail.2018.04.008.

15. Mardiah, Rivany R. Cost Recovery Rate Tarif Rumah Sakit dan Tarif INA-CBG' $s$ Berdasarkan Clinical Pathway pada Penyakit Arteri Koroner di RS Pemerintah A di Palembang Tahun 2015. 2015;175-84.

16. Wijayanti AI, Sugiarsi S. Analisis Perbedaan Tarif Riil dengan tarif Paket INA-CBG pada Pembayaran Klaim Jamkesmas Pasien Rawat Inap di RSUD Kabupaten Sukoharjo. J Manaj Inf Kesehat. 2013;1-10.

17. Sari RP. Perbandingan Biaya Riil dengan Tarif INA-CBGs dan Analisis Faktor yang Mempengaruhi Biaya Riil pada Pasien Diabetes Mellitus Rawat Inap Jamkesmas di RSUP Dr. Sardjito Yogyakarta. J SPREAD. 2014;4(April):61-70.

18. Indriani D, Kusnanto H, Ghufron A, Kuntoro M, Kesehatan F, Universitas M, etal. TarifINACBGs dan Biaya Riil Diagnosis Leukemia The Effect of Laboratory Cost to Gap Price Between INA-CBGs Reimbursement and Itemized Bill in Leukemia Diagnosis. J 
Kesehat Masy Nas. 2013;7(10):440-6.

19. Budiarto W, Sugiharto M. Biaya Klaim INA CBGs dan Biaya Riil Penyakit Katastropik Rawat Inap Peserta Jamkesmas di Rumah Sakit Studi di 10 Rumah sakit Milik Kementerian Kesehatan, Januari - Maret 2012. Bul Penelit Sist Kesehat. 2013;16(1):58-65.

20. Rahayuningrum IO, Tamtomo D, Suryono A. Comparison Between Hospital Inpatient Cost and INA-CBGs Tariff of Inpatient Care in the National Health Insurance Scheme in Solo , Boyolali and Karanganyar Districts , Central Java. J Heal Policy Manag [Internet]. 2016;1(2):102-12. Available from: https://doi. org/10.26911/thejhpm.2016.01.02.05\%0ACo mparison.
21. Hasanah U, Mahawati E, Ernawati D. Analisis Perbedaan Klaim INA-CBGs Berdasarkan Kelengkapan Data Rekam Medis Pada Kasus Emergency Sectio Cesaria trimester I tahun 2013 di RSUD KRT Setjonegoro Kabupaten Wonosobo. J Manaj Inf Kesehat Indones. 2013;1(2):53-9.

22. Kusdiandi D. Analisa Biaya Dalam Pengobatan TB Paru Di Rumah Sakit Persahatan Jakarta. TESIS. 2009; x, $52 \mathrm{hlm}$.

23. Öker F, Özyapici H. A New Costing Model in Hospital Management. Health Care Manag (Frederick) [Internet]. 2013;32(1):23-36. Available from: http://content.wkhealth.com/ linkback/openurl?sid=WKPTLP:landingpage \&an=00126450-201301000-00004. 